\title{
Factors of the Internal Environment and Their Impact on Organizational Excellence in the Public Universities in Southern Jordan from the Point of View of Workers
}

\author{
Eyad Taha Al - Rawashdeh ${ }^{1}$ \\ ${ }^{1}$ Prof., Business Administration Department, Business school, Tafila Technical University, Jordan \\ Correspondence: Eyad Taha Al - Rawashdeh, Prof., Business Administration Department, Business school, \\ Tafila Technical University, Jordan.
}

Received: February 27, 2019

Accepted: March 26, 2019

Online Published: March 28, 2019

doi:10.5539/ibr.v12n4p175

URL: https://doi.org/10.5539/ibr.v12n4p175

\begin{abstract}
This study aimed at analyzing the internal environment factors and their impact on organizational excellence in the public universities in southern Jordan from the point of view of the workers.

To achieve the objectives of the study, a questionnaire was developed to cover the study variables. The study was conducted on a community consisting of (4) public universities distributed in the southern governorates: Mu'tah University, Tafila Technical University, Al Hussein Bin Talal University, the University of Jordan-Aqaba Branch.

Administrative employees at the middle administrative levels reached (301). The researcher conducted a comprehensive survey of the study community through using the analytical descriptive statistic methods, by using the Statistical Package for the Social Sciences (SPSS).

The study reached a number of results, most important are: The general arithmetic mean of the respondents' perceptions of the dimensions of the internal environment factors in public universities in southern Jordan has reached a medium rating. Also, the general arithmetic mean of the respondents' perceptions of the dimensions of organizational excellence in the public universities in southern Jordan reached a medium rating. Among other results, there is a statistically significant positive relationship between the independent variable (internal environment factors), and its different dimensions and the dependent variable (organizational excellence) and its different dimensions.

In light of the results of the study, the study recommended a number of recommendations, most important are: the necessity of preparing a working environment and its factors and the appropriate conditions that increase the organizational excellence, paying attention to developing the capabilities of the employees and training them according to studied scientific programs as well as the need to increase the volume of expenditure on research and development activities, because spending on such activities has become an investment spending.
\end{abstract}

Keywords: internal environment factors, organizational excellence, public universities in southern Jordan

\section{Introduction}

The internal work environment represents one of the main challenges that any organization - regardless of its activities, work or culture - must address within the framework of determining the future strategies and the overall objectives of the organization. This will positively affect the efficiency of the job performance of its employees both at the level of the individual and the organization through the good balance between an individual's potential and the work he performs in an organized, continuous and stimulating manner.

The process of analyzing the internal environment of the organization is of a particular importance because it identifies the potential of the Organization, both material and human, and it also identifies the Organization's strengths and weaknesses, which help identify the Organization's position compared to competing organizations.

Organizational excellence has become a necessity for organizations success, especially as the interest in organizational excellence comes from the need of these organizations to find ways and means to identify the obstacles they face if they arise, and to look into the sensitivity of the role it plays and its importance in achieving creativity and excellence in organizations. 


\subsection{The Study's Problem}

The internal environment is the group of human, material and moral elements within the organization that interact with each other in order to achieve the production that the Organization presents to the market, and it is working towards achieving the goals for which it has been established. Management has the ability to control the internal environment. The internal environment is represented in the cultural level of the organization.

In order to illustrate the problem of study more clearly, the following question should be asked:

Do the factors of the internal environment of the organization have an impact on organizational excellence?

\subsection{The Objectives of the Study}

The research aims at achieving the following:

1- Present an appropriate theoretical framework that illustrates the impact of internal environmental factors in organizational excellence.

2- Present recommendations and proposals to decision-makers aimed at enhancing the excellence of the universities of the research.

3- Determine the relationship and impact between the internal environment and excellence in the universities of the research.

\subsection{The Importance of Study}

The study derives its importance from the following points:

1- The importance of the variables of the research, represented in the factors of the internal environment and organizational excellence.

2- Clarifying the impact of internal environmental factors on organizational excellence.

3- The importance of the results of the correlation and influential relationships between the variables of the study, which will explain the picture to decision makers in public universities in southern Jordan over the most influential and less influential and strongest and weakest correlated parts to provide a clear picture of the aspects that should be given greater attention and given priority.

\subsection{Study Questions}

To achieve the objectives of this study, the problem stems from the following main question:

What is the level of the dimensions of the internal environment factors on organizational excellence in the public universities in southern Jordan from the point of view of workers?

The sub-questions arising from the main question are as follows:

Question 1: What is the level of respondents' perceptions of the concept of internal environment factors in its dimensions (production processes, human resource management, research and development, management information systems) from the point of view of employees in public universities in southern Jordan?

Question 2: What is the level of respondents' perceptions of the concept of organizational excellence in its dimensions (excellence of leadership, excellence of subordinates) from the point of view of employees in public universities in southern Jordan?

\subsection{The Study's Hypotheses}

The first main hypothesis: There is no statistical significant impact at the level of significance $(\alpha \leq 0.05)$ for the dimensions of internal environment factors (human resource management, research and development, management information systems) on organizational excellence in its dimensions (excellence of leadership, excellence of subordinates) in public universities in southern Jordan.

The following sub-hypotheses emerge:

1- There is no statistically significant impact at the significance level of ( $\alpha \leq 0.05$ ) of internal environmental factors, by its dimensions, (human resource management, research and development, management information systems) on the excellence of leadership as one of the dimensions of organizational excellence in the public universities in southern Jordan.

2- There is no statistically significant impact at the significance level $(\alpha \leq 0.05)$ of environmental factors, by its dimensions, (human resource management, research and development, management information systems) on the excellence of subordinates as one of the dimensions of organizational excellence in the public universities in 
southern Jordan.

\section{Theoretical Framework and Previous Studies}

\subsection{The Concept of the Internal Environment}

The internal environment means having a detailed look at the organization to determine performance levels , strengths and weaknesses for all the resources it is dealing with now or in the near future. The analysis must be objective in order to give the correct picture of the Organization's real potential, known as strengths and weaknesses. (Barney, 1997)

\subsection{Internal Environment Factors}

\section{1- Production processes:}

Production and operations management is defined as the process of managing the resources required for the production of a commodity or service that the organization provides to the market. Special strategies are concerned with production, response time and delivery. Through these strategies, the organization becomes able to create a strategic position that distinguishes it from competitors. Production strategies are concerned with purchase operations, designing and using machinery and production facilities, as well as production control.

2- Human resources management:

Human resources management in business organizations seeks to improve compatibility and harmony between individuals in jobs or business. The quality of this compatibility affects several critical variables: job performance, employee satisfaction, and workers turnover.

Therefore, Human resources management is interested in selecting and training new employees, evaluating the performance of the employees, providing the possibility of promotion for employees, attracting people and future manpower planning. This management also plays a key role in managing salaries and wages, negotiating with unions, designing work and morale of the employees. This requires that the management be qualified to use trend studies and methods of reviewing the other results to assess the satisfaction of the employees about their work and jobs regarding the work to be done in each job in terms of quality and quantity.

Human resources management must be particularly able to improve the quality of work conditions in the enterprise.

3- Research and development:

The function of continuous development in the activities of the organization is one of the basic and fundamental functions. Its activity relates to the development of knowledge for management and employees, the design of new products and the development and enhancing the existing producing processes in the organization. Therefore, to evaluate this activity, it is necessary to study and analyze the following main fields:

1- The focus of research and development activity, is it applied on theoretical scientific researches or field and applied reasearches?

2- The nature of the relationship between the research and development unit and other functional units in the organizations.

3- The degree of strength of research and development activity in the organization.

4- The expected time range for obtaining results through what this activity does.

5- The role of this activity in creating the competitive advantage of the areas of work of the Organization.

4- Management information systems:

Management information systems are concerned with the design and management of information flow in the enterprise, with the aim of making rational decisions that maximize the organization's wealth, improve its performance and strategic position, facilitate the task of following up on technological developments and adapting to environmental changes.

This system collects, saves, analyzes and places data and information in an integrated information base in a way that helps answer a set of strategic and operational questions. Management information systems can be used for the following purposes: (Murdick, 1980)

1. Establish a base for analyzing primary warning signals that appear internally or externally. Each information system has a database that is used by other departments of the facility.

2. Seek to automate routine office work and to obtain the disclosure of wages and salaries and inventory reports 
and other records, thus reducing the need for staff.

3. Assist administrators in making routine decisions. The establishment of a schedule of orders, defining machine orders and the re-ordering of materials are routine tasks that can be automated by conducting a detailed analysis of the flow of work in the organization.

4. Provide the necessary information to make strategic decisions, using computers in analysis process and evaluation of strategic alternatives. This increased the need for decision-support systems to allow greater interaction between computers and users.

\subsection{Organizational Excellence}

Organizational excellence is defined as the ability of organizations to contribute and strategically compete through excellence in their performance and solving problems, and then achieving their objectives effectively in a distinguish way from other organizations (Al-Dala'ein, 2010).

Excellence in knowledge possessed by individuals is the focus of the work of organizations, which contributes to the organizations' continued excellence over global best practices in performing their functions, knowing capabilities of its competitors as well as external strengths and weaknesses and the surrounding environment (Hassoni, 2010).

Organizational excellence is also defined as: a state of managerial innovation and organizational superiority, achieving high and exceptional levels of performance and implementation of production, marketing, financial and other processes in the organization, and thus gain achievements that outperform competitors, and satisfy customers and all stakeholders in the organization.( An-nsour, 2010).

\subsection{Objectives of Organizational Excellence}

Organizational excellence is concerned with achieving many objectives in the organizations, the most important of which are:

1. Linking the Organization' strategies at various administrative levels to achieve concrete positive results through outstanding initiatives to raise the level of the organization, and achieve competitive advantage.

2. Contributing to the management of organizational change, and transferring the organizations from their current status to a better and competitive one, characterized by creativity, innovation and excellence.

3. Achieving the objectives of the organizations and drawing up methodological plans for best practices with minimum costs and efforts.

4. Examining ways to implement the methodologies of opportunities for improvement and development, at the level of the organization and at the level of Individuals, through excellence applications.

5. Disseminating best practices, instilling a sense of responsibility in partnership requirements towards society and providing community services.

6. Achieving effective organizational communication in all directions, and between all levels and elements, thus achieving structural compatibility and contributing to improve performance.

7. Improving the mechanisms of solving organizational problems; such as addressing technical problems, and dealing with external and internal crises and challenges which the Organization may face.

8. Creating an environment suitable for innovation and creativity of employees, and improving the quality of work and community lives that activate the role of Organizations in raising the performance of Individuals (Al-Khrasha, Zreiqat and Nour, 2013), (Khairi, 2014).

\subsection{Organizational Excellence Dimensions}

Most researchers in the management agreed on the existence of several dimensions of organizational excellence. The most prominent are: the excellence of organizational structure, the excellence of the strategy, the excellence of service delivery, the excellence of leadership, the excellence of subordinates and the excellence of organizational culture. (Abdel Wahab, 2016)

The most important dimensions of organizational excellence:

\section{Leadership Excellence:}

Leadership has a direct impact on excellence, through excellence in leadership skills, effective business relationships and developing individuals' abilities and encouraging them towards creativity and excellence.

There is a group of activities that must be undertaken by leaders to achieve excellence in the organization; such 
as: decentralized work system which facilitates the flow of information and innovative ideas among workers and leadership without bureaucratic barriers, as well as a deep vision of the problems in one position, and awareness of mistakes, deficiencies and shortcomings, and search for solutions (Al-Buhaisi, 2014) (Abdel Wahab, 2016).

The Concept of Leadership Excellence:

Leadership excellence demonstrates the ability of organizational leaderships to define organizational performance values and expectations, identify short and long-term future directions for the organization, and encourage innovation among employees through vision, mission, objectives, communication and developing organizational performance. (Al-Nuaimi et al, 2010).

2. Excellence of Subordinates:

The subordinates are the source of wealth. They are a combination of characteristics represented in: (abilities, skills, competencies, experiences). Therefore, they are the most valuable sustainable asset, the most important resource for the organization to invest in and the perfect use of these characteristics.

The Concept of Subordinates excellence:

The excellence of subordinates is a practice based on the concepts of intrinsic excellence, development, continuous learning, innovation, participation and responsibility towards society (Jamil and Sfeir, 2011). It demonstrates what the workers have of knowledge, skills, interests, values, attitudes and motivations which result in the effective performance of this employee, in addition to dedication and seriousness in work, the ability to assume responsibility, completion of work on time and the need for supervision and guidance. The employee's knowledge structure is constantly changing as a result of the impact of the processes of education, improvement and development. (Mahmoud, 2014).

\section{Previous Studies}

Ben Salem, Sleimani, Douly study (2018) The Effect of Organizational Excellence Methods on Contextual Performance, Bashar Branch, Case Study of the National Fund for Social Security (CASNOS).

The aim of this study was to find the positive relationship between the methods of organizational excellence (training, empowerment, incentives) and contextual performance in general in all of its dimensions within the economic institution.

This study was based on a questionnaire distribution in the institution under study. The study was limited to a sample of social security workers for non-action consisting of 46 workers from different levels of employment. A statistical program represented in ( the social statistical package) was used to process the data and analyze the results, and the hypothesis was established that there is a strong relationship between the methods of organizational excellence and contextual performance.

Al-Ghamdi study (2018)" Organizational Excellence of the Leaders of Al-Baha area Schools from the Point of View of Teachers". This study aimed to identify the degree of organizational excellence among the leaders of Al-Baha area schools from the teachers point of view. The researcher used the survey descriptive approach. The community of the study consisted of (4146) teachers and the sample of the study was (345) teachers of Al-Baha area schools. The teachers were selected in a random stratified sample method.

The results showed that the evaluation of the study sample of the degree of organizational excellence among the leaders of Al Baha area schools reached a great degree. The study reached recommendations, among which are the need to encourage school principals to maintain organizational excellence in order to improve the quality of the educational product.

Al-Sarraf, Al-Shalmah study (2018), "Social Responsibility: An Approach to Achieving Organizational Excellence, A Survey Study of the Opinions of a Sample of Employees at Salam Hospital". The study aimed at examining the social responsibility as an approach to achieve organizational excellence. In order to reach the objectives of the research, questionnaires were designed and distributed to employees. The number of questionnaires distributed was (50), and an analytical descriptive approach was adopted in order to select the hypotheses.

The study concluded that there is a correlation and an impact between responsibility and organizational excellence. The results of the analysis showed a difference in the strength of the impact for each dimension of organizational excellence dimensions with social responsibility.

One of the most important recommendations of the study is to maintain good levels of the organizational excellence dimensions of the organization under research, especially the human resource, due to its impact on 
social responsibility.

Abu-Odeh study (2018) "The impact of quality of career in the achievement of institutional excellence - an applied study on civil society organizations in the Gaza Strip". The study aimed to identify the impact of quality of work in achieving institutional excellence in civil society organizations in the Gaza Strip. To achieve this aim, a questionnaire was developed of (60) paragraph. The researcher used the random stratified sample method and the sample reached (255), distributed to supervisors in civil society organizations. The mathematical averages, Pearson correlation coefficient, multiple regression analysis and mono-variance analysis were used to analyze responses of the sample.

The results revealed that there is a statistically significant relationship between the quality of career and the achievement of institutional excellence in civil society organizations. The study concluded with a number of recommendations, most important is that the civil society organizations should grant the employees the necessary promotions fairly.

Hijazee, Tanbour study (2018) " The Role of Administrative Innovation in the Organizational Excellence of the Palestinian Ministries in the Northern Governorates". This study aimed to identify the role of administrative innovation in the organizational excellence of the Palestinian ministries in the northern governorates. To achieve this, a questionnaire was distributed to (458) workers in the different ministries in the northern governorates. The results indicated that administrative innovation explains (39\%) of the organizational excellence. The results also indicated that there are no statistically significant differences in administrative innovation and organizational excellence according to the variables of gender and scientific qualification. The results also found differences between them according to the variables of experience and career position. The researchers recommended the need for administrative innovation as a strategy adopted by different ministries for excellence and quality of performance.

Abu Rahma studay (2017), entitled "The Impact of the Internal Environment Factors of the Organization on the Level of Motivation of Achievement of workers in the Services Sector of the UNRWA". This study aimed at measuring the impact of the internal environment factors of the organization on the level of motivation for achievement among workers in the service sector in the UNRWA. The study community represented UNRWA educated, not-teachers employees who are related to the services sector. (329) questionnaires were distributed. The number of questionnaires recovered was (305) which is (92.7\%).

The researcher used the Statistical Package Program (SPSS) and statistical treatment to analyze the data. The study found the most important results, which are: the level of perceptions of the study sample around the axes of internal environment factors was high. There is a significant positive correlation between the factors of the internal environment of the organization and the level of achievement motivation among the workers in the service sector in the UNRWA.

Abdul Samee'e study (2017) entitled "The impact of the internal environment factors of the Organization on the effectiveness of the practice of strategic management applied to the Social Fund for Development ( SFD )in Egypt". This study aimed at finding out the reality of strategic management in the SFD, as well as the impact of internal environment factors in the SFD on the effectiveness of the practice of strategic management. The study sample consisted of 85 employees. The study used the descriptive analytical method as a study methodology and the questionnaire as a tool for study. The study reached the following results: the Fund's objectives are inconsistent with the organizational culture prevailing there, and there is a lack of scientific methodology for strategic management.

\section{Methodology of the Study}

The study adopted the methodology of descriptive, analytical and field research. In the field of descriptive research, a desk survey was conducted to examine theoretical and field studies and researches in order to crystallize the foundations and bases of the theoretical framework and to stand at the most important previous studies, which constitute a vital extension of the study and include knowledge-based axes.

In the field of analytical field research, a comprehensive survey was carried out, and all collected data were analyzed by answering the questionnaires and using the appropriate statistical methods. The study was based on the questionnaire that was developed.

\subsection{The Study's Community and Sample}

The study community consists of all the heads of the academic departments and the managers of the administrative units in the public universities in the south of the Hashemite Kingdom of Jordan. The number of public universities operating in the south of the Kingdom reached four official universities (Mutah university , 
Hussein bin Talal university, Tafila Technical university, and University of Jordan-Aqaba Branch). The number of members of the study community was (301) respondents distributed as follows in the public universities in the south of the Kingdom. Table (1) shows the distribution of public universities in southern Jordan. The data were verified by referring to the Personnel Affairs and Statistics of Public Universities (2019), where the researcher conducted a comprehensive survey of the study community.

Table 1. Distribution of public universities in the south of the Hashemite Kingdom of Jordan (study community)

\begin{tabular}{llllll}
\hline University & Sample respondents & Distributed & Recovered & Valid for analysis & Invalid \\
\hline Mutah university & 146 & 144 & 144 & 140 & 4 \\
Hussein bin Talal university & 82 & 80 & 80 & 77 & 3 \\
Tafila Technical university & 53 & 50 & 49 & 47 & 2 \\
UJ-Aqaba Branch & 20 & 17 & 16 & 15 & 1 \\
Grand Total & 301 & 291 & 289 & 279 & 10 \\
\hline
\end{tabular}

3.2 The Study Tool

A questionnaire was developed based on the (Likert) scale of five choices ranging from totally agree and totally disagree with a relative weight (5-1). The questionnaire was divided into two main groups, the first concerned with the personal data of the respondents, while the second group is concerned with the subject of the research and includes a group of paragraphs dealing with three main axes of the independent variable of the internal environment in its dimensions (production processes, human resource management, research and development, management information systems). It will also include a number of paragraphs covering the dependent variable of the organizational excellence in its dimensions (excellence of leadership, excellence of subordinates).

\subsection{The Veracity of the Tool}

The questionnaire was presented to a number of arbitrators of teaching staff at the universities to ascertain the veracity of the questionnaire paragraphs. Their notes were taken into consideration, some paragraphs were reworded, and the required modifications were made to balance the contents of the questionnaire with their paragraphs.

\subsection{Stability of the Tool}

The internal consistency coefficient of the study instrument was extracted using the (Cronbach's Alpha) coefficient for each of the variables of the study in all their dimensions. The values of the stability coefficient were high and indicated the stability and consistency between the paragraphs of the tool.

Table (2) shows the values of the stability coefficient.

Table 2. The coefficient of internal consistency of each variable of the study in all its dimensions

\begin{tabular}{llll}
\hline Variable & Dimension & Paragraphs & Cronbach's Alpha \\
\hline Independent Variable & Human Resources Management & $5-1$ & 0.790 \\
(Internal Environmental Factors) & Research and Development & $6-9$ & 0.745 \\
& Management information systems & $10-14$ & 0.826 \\
Dependent Variable & Leadership Excellence & $15-19$ & 0.835 \\
(Organizational Excellence) & Subordinates Excellence & $20-25$ & 0.875 \\
\hline
\end{tabular}

The data in Table (2) shows that the coefficients of dimensional stability of the internal environment variable ranged from $(0.745$ to 0.826$)$. As for organizational excellence, stability coefficients ranged from ( 0.835 to 0.875), and these values are acceptable for the objectives of the current study.

\subsection{Statistical Processing}

To answer the questions of the study and to test the validity of its hypotheses, descriptive and analytical statistical methods were used, using the statistical package (SPSS.16). The statistical methods used were as follows:

The Descriptive Statistic Measures was used to describe the characteristics of the study sample based on frequency and percentages. The Variance Inflation Factory (VIF) and (Tolerance) Test were used to ensure that there was no high correlation (Multicollinarity) between independent variables. The (Skewness) test was used to ensure that the data follows (Normal Distributions). The (Multiple Regression Analysis) was used to test the validity of the study models and the effect of the independent variable and its dimensions on the dependent variable and its dimensions. The (Stepwise Multiple Regression Analysis) was used to test the entry of independent variables in the dependent variable prediction equation.

\subsection{Results}

Before the applying the regression analysis to test the hypothesis of the study, some tests were carried out in 
order to ensure the adequacy of the data for the regression analysis hypotheses. It was ascertained that there is no high correlation between the independent variables (Multicollinarity) using (Variance Inflation Factory )(VIF) and (Tolerance) test for each variable of the study variables, taking into consideration that the VIF does not exceed the value(10) and the value of (Tolerance) is greater than $(0.05)$. It was also ascertained that the data followed the (Normal Distribution) by calculating the (Skewness) coefficient, observing that the data follows the Normal distribution if the Skewness coefficient value is close to (0). Table (3) shows the results of these tests.

Table 3. VIF coefficient, Tolerance and Skewness tests

\begin{tabular}{llll}
\hline Independent Variables & VIF & Tolerance & Skewness \\
\hline Human Resources Management & 3.024 & 0.460 & -0.337 \\
Research and Development & 2.051 & 0.390 & -0.463 \\
Management information systems & 1.555 & 0.643 & -0.625 \\
\hline
\end{tabular}

It was noticed that the VIF values for all dimensions of the independent variable were less than (10) and ranged from (1.555 to 3.024). The Tolerance values ranged from (0.390 to 0.643), and this is an indicator that there is no high correlation (Multicollinarity) between the dimensions of the independent variable. It was ascertained that the data followed the normal distribution, by calculating the (Skewness) coefficient where the values were less than (1). The validity of the model was also validated to test the hypotheses of the study.

The main first hypothesis: There is no statistically significant impact at the level of significance of $(\alpha \leq 0.05)$ of the dimensions of the internal environment (Human Resource Management, Research and Development, Management Information Systems) on organizational excellence in its dimensions (excellence of leadership, excellence of subordinates) in public universities in southern Jordan.

Table 4. Results of multiple regression analysis to test the impact of the internal environment with its different dimensions on organizational excellence

\begin{tabular}{llllll}
\hline Internal Environment Dimensions & B & Standard error & Beta & t value & $\begin{array}{l}\text { Statistical } \\
\text { Significance }\end{array}$ \\
\hline Human Resources Management & 0.246 & 0.081 & 0.178 & 3.034 & $* 0.003$ \\
Research and Development & 0.268 & 0.064 & 0.238 & 4.320 & $* 0.000$ \\
Management information systems & 0.120 & 0.069 & 0.091 & 1.682 & 0.093 \\
\hline
\end{tabular}

* significant at significance level of $(\alpha \leq 0.05)$

The statistical results in Table (4), following-up on beta coefficients and testing $(t)$ indicate that the following sub-variables related to (human resource management, Research and development) are the most important dimensions of the internal environment affecting organizational excellence, in terms of the beta coefficients for these variables as shown in the table and in terms of the increase in the calculated values of (t) from their tabular value at the level of significance $(\alpha \leq 0.05)$.

The results indicated that the sub-variable (Management Information Systems) has no effect on organizational excellence in terms of the calculated value $(t)$ and the associated significance level at the level of significance $(\alpha \leq 0.05)$. So, the main hypothesis is partially rejected, which states that there is no statistically significant effect at the level of $(\alpha \leq 0.05)$ of the dimensions of the internal environment (human resource management, research and development, management information systems) on organizational excellence in its dimensions (Excellence of Leadership, Excellence of Subordinates) in public universities in southern Jordan.

The Stepwise Multiple Regression analysis was conducted by the researcher to determine the importance of each independent variable in contributing to the mathematical model, which represents the effect of internal environment factors (production processes, human resource management, Research and Development, Management Information Systems) on organizational excellence in public universities in southern Jordan. Table (5) shows the results of this.

Table 5. Results of Stepwise Multiple Regression analysis to predict organizational excellence through the dimensions of the internal environment

\begin{tabular}{|c|c|c|c|c|}
\hline $\begin{array}{l}\text { The order of entry of independent variables in } \\
\text { the prediction equation }\end{array}$ & $\begin{array}{l}\mathbf{R 2} \\
\text { value }\end{array}$ & $\begin{array}{l}\text { Calculated } \\
\text { value }\end{array}$ & $\mathbf{t}$ & t significance level \\
\hline Human Resources Management & 0.217 & 9.79 & & $* 0.000$ \\
\hline Research and Development & 0.256 & 5.10 & & $* 0.000$ \\
\hline
\end{tabular}

* significant at significance level of $(\alpha \leq 0.05)$

(Management Information Systems) is out of the regression equation

Table (5) shows the order of entry of independent variables in the regression equation. Human resources management ranked first and interpreted $(21.7 \%)$ of the variance in the dependent variable, followed by the 
Research and development variable and explained with the Human Resources Management variable (25.6\%) of the variance in the dependent variable, as the management Information Systems were out of the regression equation.

The first sub-hypothesis: There is no statistically significant effect at the significance level of $(\alpha \leq 0.05)$ of the internal environment in its dimensions (human resource management, research and development, management information systems) on the excellence of leadership as one of the dimensions of organizational excellence in the public universities in southern Jordan.

Table 6. The results of multiple regression analysis to test the effect of independent variable dimensions (internal environment) on the dimension (leadership excellence) as one of the dimensions of organizational excellence

\begin{tabular}{|c|c|c|c|c|c|}
\hline Dependent Variable & $\mathbf{B}$ & Standard error & Beta & T calculated value & $\begin{array}{l}\text { T } \\
\text { Significance level }\end{array}$ \\
\hline Human Resources Management & 0.255 & 0.092 & 0.168 & 2.783 & $* 0.006$ \\
\hline Research and Development & 0.190 & 0.069 & 0.156 & 2.752 & $* 0.006$ \\
\hline Management information systems & 0.246 & 0.074 & 0.183 & 3.342 & $* 0.001$ \\
\hline
\end{tabular}

* significant at significance level of $(\alpha \leq 0.05)$

From the statistical results in Table (6),and from following-up on the (Beta) coefficient as well as the (t) test, it is clear that the following sub-variables (human resource management, research and development, Management information systems) have an impact on the (leadership excellence) dimension as one of the dimensions of organizational excellence, in terms of the (Beta) coefficients of these variables as shown in the table, and in terms of the increase in the calculated values of ( $t$ ) from its tabular value at the significance level of $(\alpha \leq 0.05)$.

As a result, the first sub-hypothesis is rejected, which states that there is no statistically significant effect at the significance level of $(\alpha \leq 0.05)$ of the internal environment in its dimensions (human resource management, research and development, management information systems) on the excellence of leadership as one of the dimensions of organizational excellence in the public universities in southern Jordan.

The researcher also carried out the Stepwise Multiple Regression analysis to determine the importance of each independent variable in contributing to the mathematical model, which represents the effect of the internal environment in its dimensions (human resources management, research and development, Management Information systems) on the excellence of leadership as one of the dimensions of organizational excellence in public universities in southern Jordan, and Table (7) shows the results of that.

Table 7. Results of Stepwise Multiple Regression analysis to predict leadership excellence as a dimension of organizational excellence through internal environment factors

\begin{tabular}{|c|c|c|c|}
\hline $\begin{array}{l}\text { The order of entry of independent variables in } \\
\text { the prediction equation }\end{array}$ & $\begin{array}{l}\text { R2 Value } \\
\text { Coefficient of } \\
\text { cumulative selection }\end{array}$ & Calculated t value & t significance level \\
\hline Human Resources Man & 0.156 & 8.75 & $* 0.00$ \\
\hline Research and Development & 0.223 & 4.71 & $* 0.00$ \\
\hline Management Information Systems & 0.253 & 2.26 & $* 0.024$ \\
\hline
\end{tabular}

* significant at significance level of $(\alpha \leq 0.05)$

Table (7) shows the order of entry of independent variables in the regression equation. Human resources management ranked first and explained $(15.6 \%)$ of the variance in the dependent variable, followed by the Research and development variable and explained with the variable of the production processes $(22.3 \%)$ of the variance in the dependent variable, and finally entered the Management Information Systems and explained with the previous variables $(25.3 \%)$.

The Second Sub-Hypothesis: There is no statistically significant effect at the level significance of $(\alpha \leq 0.05)$ of the internal environment in its dimensions (human resource management, research and development, management information systems) in the excellence of subordinates as one of the dimensions of organizational excellence in the public universities in southern Jordan.

Table 8. The results of multiple regression analysis to test the effect of independent variable dimensions (internal environment factors) on the excellence of subordinates as one of the dimensions of organizational excellence

\begin{tabular}{llllll}
\hline Dependent Variable & B & Standard error & Beta & T calculated value & $\begin{array}{l}\text { T } \\
\text { Significance level }\end{array}$ \\
\hline Human Resources Management & 0.257 & 0.101 & 0.131 & 3.105 & $* 0.036$ \\
Research and Development & 0.285 & 0.076 & 0.201 & 4.445 & $* 0.001$ \\
Management information systems & 0.130 & 0.086 & 0.095 & 1.649 & 0.100 \\
\hline
\end{tabular}

* significant at significance level of $(\alpha \leq 0.05)$ 
The statistical results in Table (8), following -up on of (Beta) coefficients and (t) test show that the following sub-variables related to (human resource management, Research and Development) have an impact on the (subordinate excellence dimension) as a dimension of the organizational excellence, in terms of the (Beta) coefficients of these variables, as shown in the table, and in terms of the increase in the calculated values of (t) from its tabular value at the level of $(\alpha \leq 0.05)$.

The results also show that there is no impact of Management Information Systems on predicting the dimension of subordinates excellence as a dimension of organizational excellence.

Therefore, the second sub-hypothesis, which states that there is no statistically significant effect at the level of significance of $(\alpha \leq 0.05)$ of the internal environment in its dimensions (human resource management, research and development, Management Information Systems ) on the subordinates excellence as a dimension of Organizational Excellence, is partially rejected.

The researcher also conducted the stepwise multiple regression analysis to determine the importance of each independent variable in contributing to the mathematical model, which represents the effect of the internal environment (Human resources management, Research and development, Management Information Systems) on the dimension of (subordinates excellence) as a dimension of the Organizational excellence in the public universities in southern Jordan. Table (9) shows the results of this.

Table 9. Results of Stepwise Multiple Regression Analysis to predict the dimension of subordinates excellence as a dimension of organizational excellence through internal environmental factors

\begin{tabular}{llll}
\hline $\begin{array}{l}\text { The order of entry of independent variables in the } \\
\text { prediction equation }\end{array}$ & $\begin{array}{l}\text { R2 Value } \\
\text { Coefficient of cumulative } \\
\text { selection }\end{array}$ & $\begin{array}{l}\text { Calculated } \\
\text { value }\end{array}$ & $\begin{array}{l}\mathbf{t} \text { significance } \\
\text { level }\end{array}$ \\
\hline $\begin{array}{l}\text { Human Resources Management } \\
\text { Research and Development }\end{array}$ & 0.152 & 8.61 & $* 0.00$ \\
\hline
\end{tabular}

* significant at significance level of $(\alpha \leq 0.05)$

- (Management of Information Systems) is out of the Regression Equation

Table (9) shows the order of entry of the independent variables in the regression equation. Human resources management ranked first and explained (15.2\%) of the variance in the dependent variable, followed by the Research and development variable and explained with the variable of production processes $(19.5 \%)$ of the variance in the dependent variable. The Management Information Systems variable is out of the regression equation.

\section{The Results}

1. The results indicated that the perceptions of the members of the study sample of the internal environment factors in the public universities in the south of the Hashemite Kingdom of Jordan came, on the overall level, at a medium degree.

2. The results indicated that the perceptions of the members of the study sample of the dimensions of organizational excellence in the public universities in the south of Jordan are of a medium, overall level

3. The results showed the following independent variables are related to (human resource management, research and development). The (human resources management) dimension ranked first in terms of the calculated value of ( $\mathrm{t}$ ), followed by (research and development) dimension of the variance of the organizational excellence in the second place.

In addition, the results indicate that there is no statistically significant effect of the (management information systems) dimension on organizational excellence in the public universities in the south of the Kingdom. Consequently, the main hypothesis is partially rejected regarding the Management information systems in terms of the (t) calculated value.

4. The results showed that the following variables related to the dimensions of the internal environment factors (human resource management, research and development, management information systems) have an effect on the excellence of leadership as one of the dimensions of organizational excellence in the public universities in the south of the Kingdom. (Human Resources Management) ranked first, followed by (Research and Development), followed by (Management Information Systems) in third place in the variance of the dependent variable( Leadership Excellence).

5. The results showed that the following variables related to the dimensions of internal environment factors (human resource management, research and development) have an effect on the excellence of subordinates as 
one of the dimensions of organizational excellence in the public universities in the south of the Kingdom. (Human resources management) ranked first, followed by (research and development) in the second place. The (management information systems) came out of the equation, therefore, the hypothesis was partially rejected because the calculated value of ( $\mathrm{t}$ ) was (1.649).

\section{Recommendations}

1. Enhancing attention to analyzing the internal environment in order to identify strengths and weaknesses and overcome them, identify and boost strengths, and benefit from them in achieving organizational excellence.

2. The need to increase the volume of expenditure on research and development activities, where spending on these activities represents investment spending.

3. Developing fact-based management methods as well as developing information systems and decision-support.

4. Pay attention to developing the capabilities of the staff and training them according to studied scientific programs.

5. The necessity of creating the working environment and its factors and the appropriate conditions that increase the organizational excellence.

\section{References}

Abdul, S. R. (2014). the Effect of the internal environment factors of the organization on the effectiveness of the practice of strategic management applied to the Social Fund for Development in Egypt (unpublished master thesis), Banha University, Egypt

Abdul, W., \& Mahmoud, O. (2016). Administrative transparency and its impact on organizational excellence. Al Mustansiriya Journal of Arab and International Studies, 53, 128-164.

Abu Odeh, M. I. I. (2018). The Effect of Quality of Career in Achieving Institutional Excellence, Applied Study on Civil Society Organizations in the Gaza Strip, Unpublished Master Thesis, Islamic University of Gaza, Palestine.

Abu, R., \& Ahmed, Y. (2017). Influence of the internal environment factors of the organization on the level of achievement motivation among the workers in the service sector in UNRWA, (unpublished master thesis), Islamic University of Gaza, Palestine.

Al - Dala'een, A. (2010). The Effect of Administrative Empowerment in Organizational Excellence: A Field Study in Jordan Telecom Company. Studies of Administrative Sciences, 37(1), 64-92.

Al-Beheisy, A. M. M. (2014). The role of empowering workers in achieving institutional excellence: A field study on technical colleges in the Gaza Strip governorates. Unpublished MA thesis, Faculty of Economics and Science.

Al-Ghamdi, R. A. S. (2018). Organizational Excellence among the leaders of Al-Baha area schools from the point of view of teachers. International Journal of Educational and Psychological Studies, 3(2).

Al-Khrasha, Y. K., Azreiqat, K. K., \& Nour, M. I. (2013) The impact of change factors on the achievement of organizational excellence: Arab Potash Company as an example. Management Science Studies, 40(2) 211-238.

Al-Naimy, M. A. A., Al-Zu'bee, A. A., Al-Zu'bee, H. M. (2010). Suggest a model for performance standards and measure their impact in achieving excellence in Jordanian private universities. Journal of the Union of Arab Universities, 56, 365-405.

Annsour, A. S. (2010) The Impact of the Organization's Characteristics on Achieving Institutional Excellence: An Applied Study in the Jordanian Ministry of Higher Education and Scientific Research. Unpublished MA thesis, Business School, Middle East University, Amman.

ASsarraf, S. N. E., \& Ashalmeh, M. A. A. (2018). Social Responsibility, an approach to Achieve of Organizational Excellence, A Survey of the Opinions of a Sample of Workers in Al Salam Hospital, Tikrit Journal of Administrative and Economic Sciences, 1(41), 77-110.

Barney, J. B. (1997). Gaining and sustaining competitive advantage, reading: mass: Addison Wesley, pp.145-164.

Ben Salem, S., \& Elias, D. S. (2018) The Effect of Organizational Excellence on Contextual Performance - Case Study of the National Fund of the Social Security for Non-Action. Journal of Economics of Business and Finance, 6. 
Hassouni, A. A. A. (2010). Strategic Leadership Practices and their Role in Enhancing Organizational Excellence - Analytical Study at the General Company for Mechanical Industries - Baghdad. Al-Kout Journal of Administrative and Economic Sciences, 1(2), 206-225.

Hejazi, M. H., \& Tanpur, R. S. (2018). The Role of Administrative Creativity in the Organizational Excellence of the Palestinian Ministries in the Northern Governorates. Al-Quds Open University for Administrative and Economic Research, III(9), 134-150.

Khairy, O. (2014). Organizational Excellence. Amman: Al Raya Dar for Publishing and Distribution.

Mahmoud, B. Q. (2014). In-service training and its role in improving the performance of employees at the university institution. Unpublished MA thesis. Mohammed Khaydar University, Biskra, Algeria.

\section{Copyrights}

Copyright for this article is retained by the author(s), with first publication rights granted to the journal.

This is an open-access article distributed under the terms and conditions of the Creative Commons Attribution license (http://creativecommons.org/licenses/by/4.0/). 